\title{
Modification of PTFE nanopowder by controlled electron beam irradiation: A useful approach for the development of PTFE coupled EPDM compounds
}

\author{
M. S. Khan*, D. Lehmann, G. Heinrich \\ Leibniz Institute of Polymer Research Dresden, Hohe Str. 6, D-01069 Dresden, Germany \\ Received 30 January 2008; accepted in revised form 9 March 2008
}

\begin{abstract}
Low-temperature reactive mixing of controlled electron beam modified Polytetrafluoroethylene (PTFE) nanopowder with Ethylene-Propylene-Diene-Monomer (EPDM) rubber produced PTFE coupled EPDM rubber compounds with desired physical properties. The radiation-induced chemical alterations in PTFE nanopowder, determined by electron spin resonance (ESR) and Fourier transform infrared (FTIR) spectroscopy, showed increasing concentration of radicals and carboxylic groups $(-\mathrm{COOH})$ with increasing irradiation dose. The morphological variations of the PTFE nanopowder including its decreasing mean agglomerate size with the absorbed dose was investigated by particle size and scanning electron microscopy (SEM) analysis. With increasing absorbed dose the wettability of the modified PTFE nanopowder determined by contact angle method increased in accordance with the $(-\mathrm{COOH})$ concentration. Transmission electron microscopy (TEM) showed that modified PTFE nanopowder is obviously enwrapped by EPDM. This leads to a characteristic compatible interphase around the modified PTFE. Crystallization studies by differential scanning calorimetry (DSC) also revealed the existence of a compatible interphase in the modified PTFE coupled EPDM.
\end{abstract}

Keywords: mechanical properties, PTFE nanopowder, EPDM, electron beam irradiation, compatibility

\section{Introduction}

Polytetrafluoroethylene (PTFE) finds an exceptional position in plastic industry due to its outstanding chemical and heat resistance, electrical insulation and its significantly low friction coefficient. These properties recommend PTFE for numerous and diverse applications [1]. Both elastomeric and thermoplastic fluoropolymers find a wide use especially in automotive applications such as seals, O-rings and gasket etc. [2]. It is also blended with other polymers or reinforced as a composite material for special purpose applications [3-5]. However, its inherently low adhesion and inert behaviour limit its dispersion and compatibility with other materials. Therefore, surface modification of PTFE to enhance its wettability and compatibility is a prerequisite for its effective utilization in other compounds. New approaches were considered to surface modification of PTFE via different procedures [6-10]. Significant developments were also made both in the synthesis and manufacturing of new commercial fluorpolymers with improved mechanical properties [11-12]. However, electron beam modification provides a simple and effective method for modification of PTFE powder [13-20]. Recently, newly developed chemically coupled PTFE-PA compounds have opened a new way in producing high performance wearresistant materials [21-23]. A new class of potential wear-resistant materials based on modified PTFE powder filled SBS, NBR and EPDM compounds were also produced [24]. Modified PTFE

*Corresponding author, e-mail: khan@ipfdd.de

(C) BME-PT and GTE 
powder was specially utilized in NBR to expand its utility as wear-resistant material for sealing applications [25]. PTFE micropowders produced by emulsion polymerization are low-molecular weight fine coagulated powder commonly used as an additive in variety of applications [26-27]. In the previous study, PTFE coupled EPDM compounds were produced by reactive mixing of pre-modified PTFE nanopowder with EPDM [28]. In the present work the influence of dose-controlled agglomerate size, structural morphology and interfacial compatibility of PTFE nanopowder on the physical properties of the resulting modified PTFE-EPDM blends are presented. These investigations are of extreme importance especially in the development of new rubber compounds which require optimization of both the physical and tribological properties [29-30]. It has been shown that the desired physical properties can be achieved simply by controlled modification of PTFE nanopowder.

\section{Materials and experimental}

\subsection{Materials}

Both EPDM (Buna EP G 6850) with ethylidene norbornene (ENB) content $7.7 \mathrm{wt} \%$; ethylene content $51 \mathrm{wt} \%$; Mooney viscosity, ML $(1+4)$ at $125^{\circ} \mathrm{C}, 60$; ash content $0.2 \mathrm{wt} \%$; specific gravity, 0.86; and peroxide (Perkadox 14-40 MB GR) were supplied from Lanxess Deutschland $\mathrm{GmbH}$, Germany while coagent (R-20S/Saret 634C) was used from Sartomer, USA. Algoflon L100X an emulsion grade received from Solvay Solexis S.p.A, Italy is an agglomerated white PTFE nanopowder with the bulk density and surface area of $0.25-0.44 \mathrm{~g} \cdot \mathrm{cm}^{-3}$ and $26 \mathrm{~g} \cdot \mathrm{m}^{-2}$, respectively.

\subsection{Modification of PTFE nanopowder}

PTFE nanopowder was modified with absorbed doses of 20,100, 200, 300, 400 and $500 \mathrm{kGy}$ with the help of ELV-2 electron beam accelerator from Budker Institute of Nuclear Physics, Novosibirsk, Russia, installed at the Leibniz Institute of Polymer Research Dresden. The electron beam treatment was carried out in air and at room temperature with an absorbed dose of $2.5 \mathrm{kGy}$ per pass and at an average dose rate of about $10 \mathrm{kGy} / \mathrm{h}$. These treatment parameters were considered in order to avoid excess temperature rise which might favour deactivation of the radical formation as well as to control agglomerate size and chemical structure via absorbed dose. Further information about the electron accelerator (ELV-2) facility can be found in [18].

\subsection{PTFE nanopowder characterization}

The number of free radicals was determined with the help of MiniScope MS200 electron spin resonance (ESR) instrument from Magnettech Limited, Germany. Spin numbers for each absorbed dose were calculated after four hours of electron treatment. Fourier Transform Infrared Spectrometer (FTIR) spectra were recorded on Vertex $80 \mathrm{v}$ (Bruker) FTIR spectrometer $\left(4000-400 \mathrm{~cm}^{-1}\right.$, resolution $=2 \mathrm{~cm}^{-1}, 32$ scans per measurement) in transmission mode on $10 \mu \mathrm{m}$ thin PTFE foils to observe the chemical changes induced in PTFE nanopowder having exposed to different absorbed doses. The contact angle measurements were performed on ( $1 \mathrm{~mm}$ thin, diameter $20 \mathrm{~mm}$ ) PTFE discs with the help of OCA 40 Micro contact angle meter from DataPhysics Instrument $\mathrm{GmbH}$, Germany. The rounded discs were prepared by compressing PTFE nanopowder at room temperature under a pressure of $1 \mathrm{MPa}$. Sessile drop method was performed to determine the wettability of PTFE discs modified similarly as discussed in section 2.2. The discs were used to obtain smooth and comparable surfaces for contact angle measurement.

The particles size and their distribution were determined with the help of the particle size analyzer, Sympatec HELOS HO367 from Sympatec GmbH Germany, having a measuring range of $0.5 / 0.9$ $175 \mu \mathrm{m}$. The primary and mean agglomerate size of PTFE nanopowder was $70-80 \mathrm{~nm}$ and $17.7 \mu \mathrm{m}$, respectively, as received from the supplier. Post and pre-irradiation structure morphology of the PTFE nanopowder modified to different absorbed doses were determined with the help of LEO 435 scanning electron microscope (SEM - acceleration voltage $20 \mathrm{kV}$ ) from LEO Electron Microscopy Ltd, England. SEM examination was also performed on the cryogenic surface fractured samples for the dispersion analysis of PTFE nanopowder in EPDM.

\subsection{Specimen preparation}

EPDM and $30 \mathrm{phr}$ (parts per hundred of rubber) PTFE nanopowder were first pre-mixed in a Poly- 
Lab Haake Rheomix internal mixer from Thermo Electron Corp, Germany for 5 minutes at $100^{\circ} \mathrm{C}$ and at a rotor speed of $50 \mathrm{rpm}$. Curatives including $7.5 \mathrm{phr}$ coagent and $5 \mathrm{phr}$ peroxide were added to the material on a two roll laboratory mill (Polymix 110L, Servitic, Germany) at room temperature. A constant friction ratio of 1.2 was maintained between the milling rolls. Approximately $2 \mathrm{~mm}$ thick sheets were drawn out from the mill and cured in a hot press (Fontune, Holland) under a pressure of $5 \mathrm{MPa}$ at a temperature of $170^{\circ} \mathrm{C}$ up to their corresponding optimum cure time.

\subsection{PTFE-EPDM blend characterization}

Mechanical properties including tensile strength at break, percentage elongation at break and modulus at $300 \%$ elongation were carried out according to ISO 527 at a cross-head speed of $200 \mathrm{~mm} / \mathrm{min}$ using tensile testing machine (Zwick, Germany). Hardness values were measured according to DIN 53505, using a Shore A Durometer. Indentations were made at several points for each specimen for the determination of the average hardness value. Differential scanning calorimetry (DSC) studies of the PTFE-EPDM composites were carried out using NETSCH DSC 204 from NETZSCH-Gerätebau $\mathrm{GmbH}$, Germany to analyze the influence of absorbed dose on the compatibility and dispersion in EPDM from their crystallization studies. All experiments were performed under atmospheric conditions and at a heating rate of $10 \mathrm{~K} \cdot \mathrm{min}^{-1}$ above the melting temperature of PTFE up to $330^{\circ} \mathrm{C}$. The results obtained were expressed as input energy versus temperature. Transmission electron microscopy (TEM) micrographs of the modified and non-modified PTFE filled EPDM were recorded on transmission microscope model EM910 from Carl Zeiss, Germany.

\section{Results and discussion}

\subsection{Effect of modification on the molecular structure of PTFE}

Figure 1 shows the ESR spectra of the modified and non-modified PTFE nanopowder. The ESR spectra show a systematic increase in the signal with increasing absorbed irradiation dose. Nonmodified PTFE nanopowder produced no signal due to the absence of reactive free radicals. The

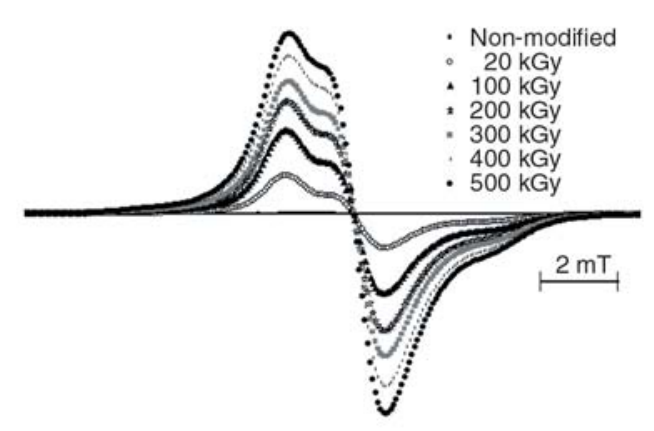

Figure 1. Electron spin resonance (ESR) spectra of PTFE nanopowder modified with differentabsorbed doses

increase in signal indicates that the radical concentration is increased with increasing absorbed dose or modification. $500 \mathrm{kGy}$ irradiated PTFE nanopowder having the highest spin numbers shows the highest number of radical concentration. Electron beam treatment generates persistent reactive free radicals and functional groups on the surface due to degradation of PTFE nanopowder by chain scission. Figure 2 visualizes the radiation induced degradation of PTFE in the presence of air. It has been reported that PTFE undergoes $\mathrm{C}-\mathrm{F}$ and $\mathrm{C}-\mathrm{C}$ scission during energy rich electron modification process [31-32]. C-F scission results in secondary radicals while $\mathrm{C}-\mathrm{C}$ scissions produce primary free radicals. These free radicals react with atmospheric oxygen to yield stable perfluoroalkylperoxy radicals. Besides these peroxy radicals, carbonyl fluoride groups are also formed which hydrolyse in the presence of atmospheric moisture to form carboxylic acid groups $(-\mathrm{COOH})$. The complete reaction mechanism can be found in [33]. Chemical changes introduced in PTFE after exposure to electron treatment were monitored by FTIR spectroscopy. Figure 3 shows several new bands in the infrared spectrum of modified PTFE. The peak at $1884 \mathrm{~cm}^{-1}$ was identified with carbonyl fluoride groups (-COF) while $1810 \mathrm{~cm}^{-1}$ are free and $1777 \mathrm{~cm}^{-1}$ associated carboxylic acid groups $(-\mathrm{COOH})$.
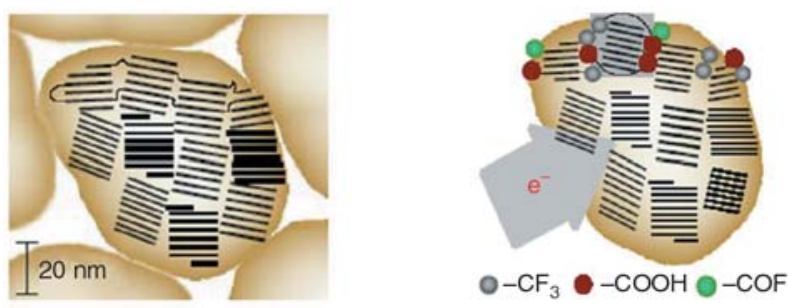

Figure 2. Radiation induced degradation of high molecular weight PTFE nanopowder 


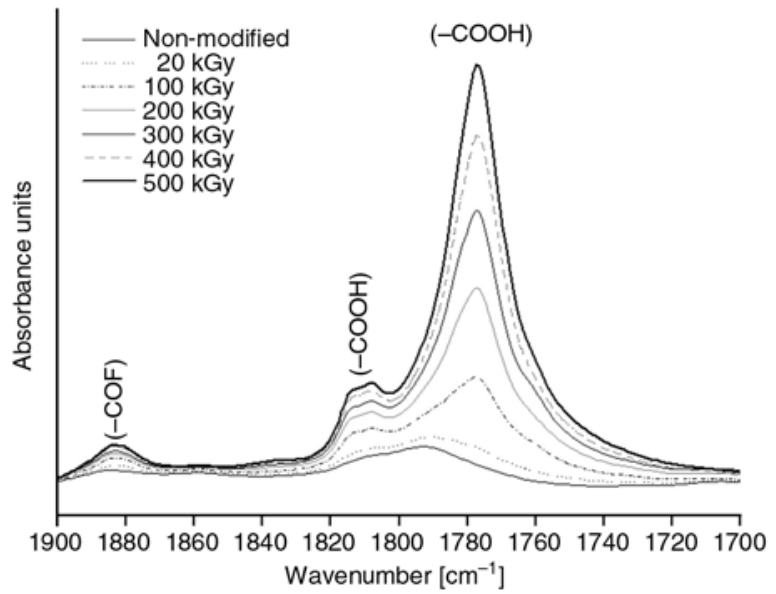

Figure 3. Infrared spectra (1900-1700 $\left.\mathrm{cm}^{-1}\right)$ of L100X (nanopowder) after modification by different absorbed doses in comparison to non-modified PTFE

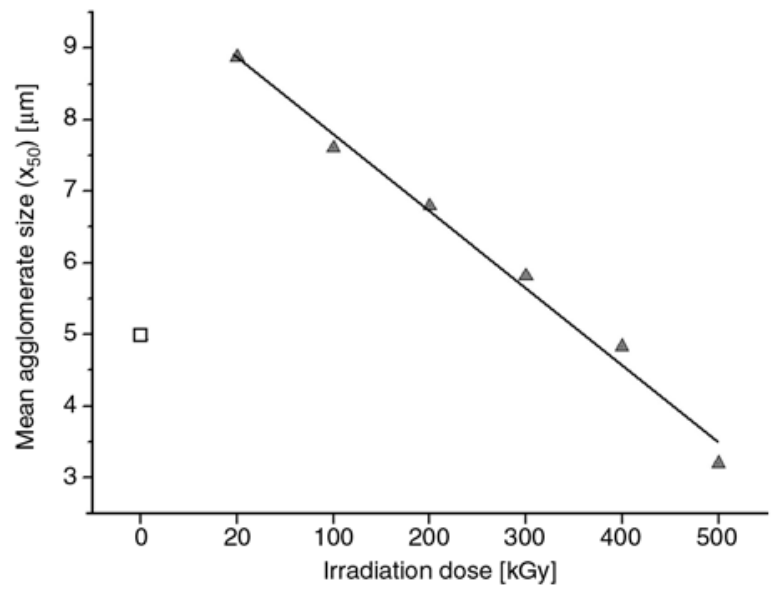

Figure 4. Mean agglomerate size of PTFE nanopowder as a function of absorbed dose (Empty box indicates non-irradiated while filled triangles indicates irradiated PTFE nanopowders)

Figure 4 shows the influence of absorbed dose on the mean agglomerate size of PTFE nanopowder. It can be seen that mean agglomerate size of PTFE nanopowder decreased systematically with absorbed irradiation dose. It suggests that mean agglomerate size of PTFE nanopowder can be controlled via absorbed dose. The decrease in agglomerate size is due to chain scission of PTFE nanopowder. High molecular weight PTFE is reduced to low molecular weight PTFE. The highest absorbed dose of $500 \mathrm{kGy}$ shows the smallest mean agglomerate size. The mean agglomerate size delivered by the supplier of virgin non-modified PTFE nanopowder was $17.7 \mu \mathrm{m}$ compared to our determined agglomerate size of $5.0 \mu \mathrm{m}$. This might be due to the ability of PTFE nanopowder to re-agglomerate as can

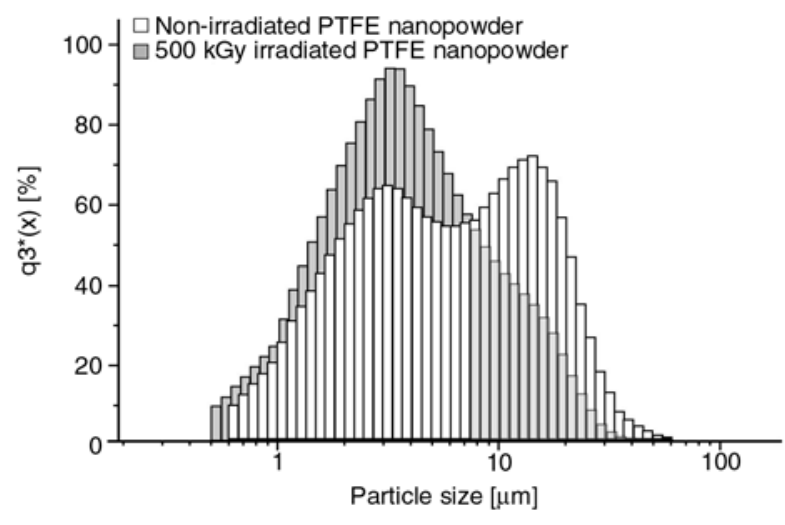

Figure 5. Particle size distribution of non-irradiated and 500 kGy irradiated PTFE nanopowder

be seen in the particle size distribution in Figure 5. The particle size distribution suggests that non-irradiated L100X PTFE nanopowder has a broad particle size distribution compared to $500 \mathrm{kGy}$ irradiated PTFE nanopowder. The non-irradiated PTFE nanopowder shows a characteristic bimodal distribution compared to unimodal distribution of 500 kGy irradiated PTFE nanopowder. This specific bimodal distribution clearly signifies that nonirradiated L100X PTFE nanopowder is mainly composed of bigger agglomerates which tend to reagglomerate. On the contrary, $500 \mathrm{kGy}$ irradiated PTFE nanopowder indicates finely dispersed smaller agglomerate particles. This can also be seen in the SEM micrographs of $500 \mathrm{kGy}$ irradiated PTFE nanopowder. Effect of absorbed dose on the agglomerate morphology of (a) non-irradiated L100X and (b) $500 \mathrm{kGy}$ irradiated PTFE nanopowder is shown in Figure 6. It is evident that the agglomerate size and morphology of these nanopowders are apparently distinguishable from each other. Non-irradiated PTFE nanopowder are huge solid-structured agglomerates formed by the random re-agglomeration of PTFE agglomerates. In comparison, $500 \mathrm{kGy}$ irradiated PTFE nanopowder shows fine homogeneous coarse particles dispersed individually over the area without the formation of huge agglomerates.

Figure 7 shows result of the contact angle measurements on PTFE nanopowders having different absorbed doses in comparison to $0 \mathrm{kGy}$ (non-modified) L100X PTFE nanopowder. The horizontal line indicates contact angle value of a typical commercial PTFE. It is observed that the water contact angles of modified PTFE discs are lower than nonmodified PTFE disc and is systematically decreas- 


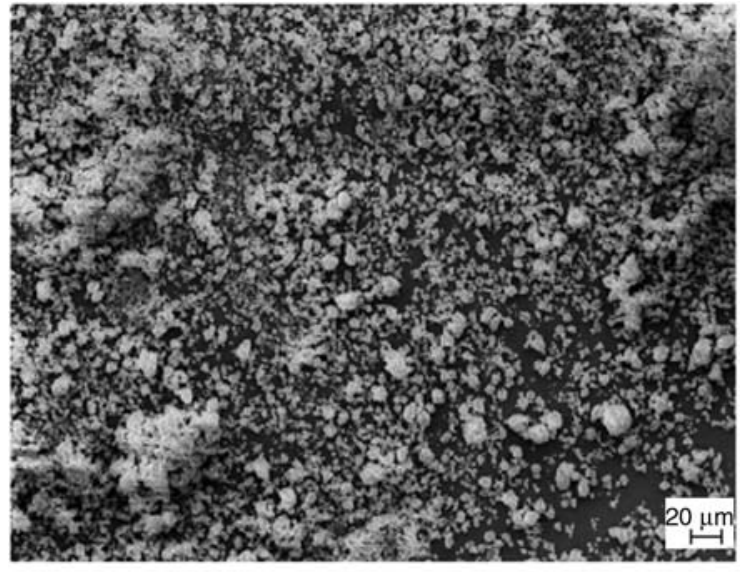

a)

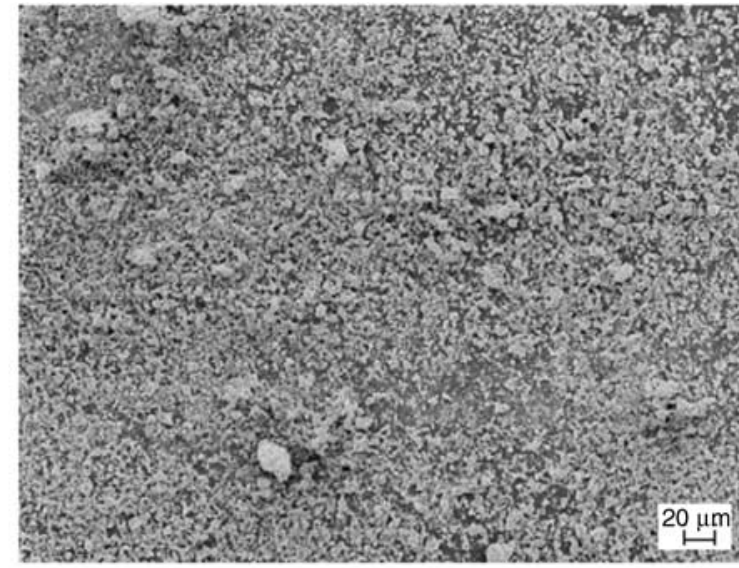

b)

Figure 6. Scanning electron micrographs of (a) non-irradiated and (b) 500 kGy irradiated PTFE nanopowder

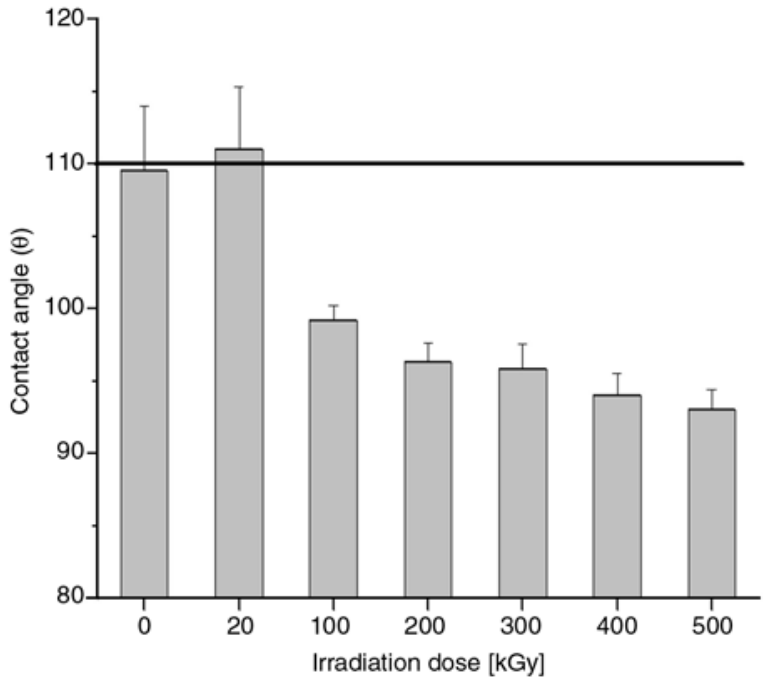

Figure 7. Effect of the absorbed dose on the contact angle of modified PTFE discs in comparison to nonmodified PTFE. The horizontal line indicates contact angle value of a commercial PTFE

ing with increasing absorbed dose. The water contact angle of $111^{\circ}$ of non-modified L100X PTFE nanopowder indicates its inherently hydrophobic behavior. Post-modification to different absorbed doses result in the decrease in contact angle from 114.8 to $92^{\circ}$ for $500 \mathrm{kGy}$ PTFE nanopowder. That is, compared with non-modified PTFE, the wettability of $500 \mathrm{kGy}$ is significantly increased. The increase in wettability is due to the strong interaction between water and the hydrophilic groups $(\mathrm{COF} / \mathrm{COOH})$ generated on the surface of PTFE nanopowder after electron treatment in the presence of air. As can be seen, increasing absorbed dose results in lower contact angles due to the generation of oxygen containing groups on the PTFE surface. Lower contact angles correspond to higher surface energy and thus higher adhesion and higher interfacial compatibility. As shown in Figure 3 an increasing absorbed dose results in higher concentration of $\mathrm{C}=\mathrm{O}$ groups $\left(1777 \mathrm{~cm}^{-1}\right)$. This shows that the chemical structure of PTFE nanopowder was changed due to electron treatment.

\subsection{Effect of structural changes on the compatibility with EPDM}

Figure 8a-8c show TEM micrographs of PTFE 0 kGy EPDM, PTFE 300 kGy-EPDM and PTFE 500 kGy-EPDM blends. The enhanced interfacial compatibility in case of PTFE 300 kGy-EPDM and PTFE500 kGy-EPDM can be seen in Figures $8 \mathrm{~b}$ and 8c. The modified agglomerate particles are embedded and enwrapped by EPDM. No clear and visible interphase can be seen between the two incompatible polymers. Slightly light and dark regions around modified PTFE powder are an indication of a reinforced compatible interphase due to radical coupling with EPDM. It is also observed that modified PTFE agglomerate acts as a PTFE core sorrounded by EPDM shell. On the other hand, PTFE0 kGy-EPDM shows non-modified PTFE nanopowder as solid embedded bodies lacking interfacial compatibility with EPDM. The interface is distinctively separated from each other. No mutual compatible interphase exists as observed in both PTFE $300 \mathrm{kGy}-\mathrm{EPDM}$ and PTFE500 kGy-EPDM blends. Modified agglomerates in case of PTFE $500 \mathrm{kGy}-E P D M$ are elongated and outstretched in a specific direction. The modified PTFE particles due to enhanced compatibility and dispersion are oriented under high-shearing during reactive blending. However, non-modified PTFE 


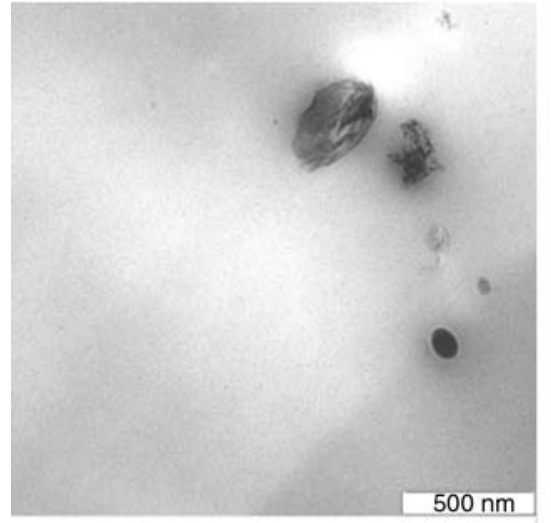

a)

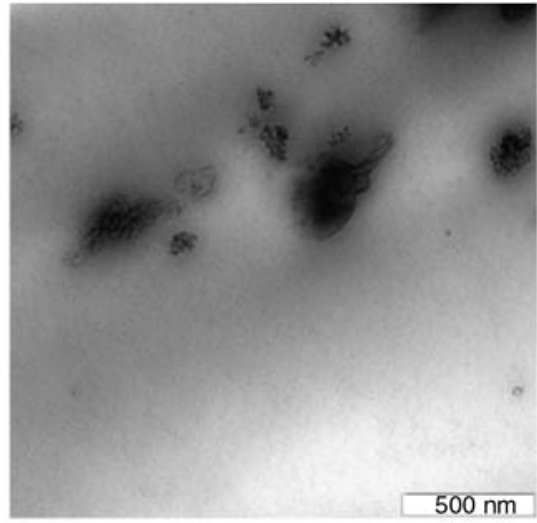

b)

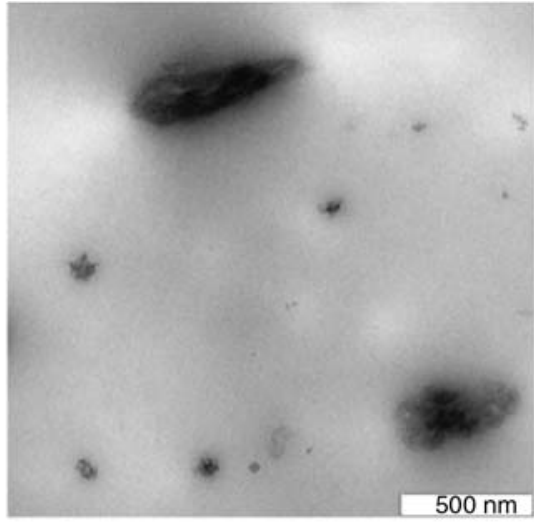

c)

Figure 8. TEM morphologies of a) PTFE 0 kGy-EPDM; b) PTFE 300 kGy-EPDM and c) PTFE $500 \mathrm{kG}_{\mathrm{y}}$-EPDM blends

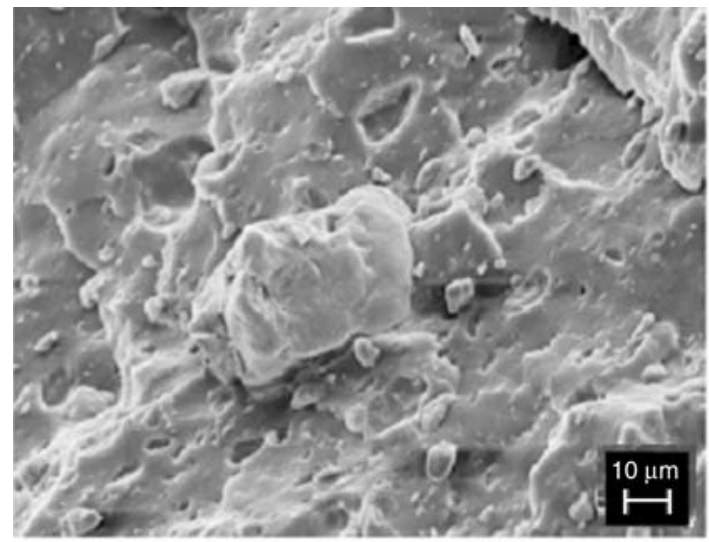

a)

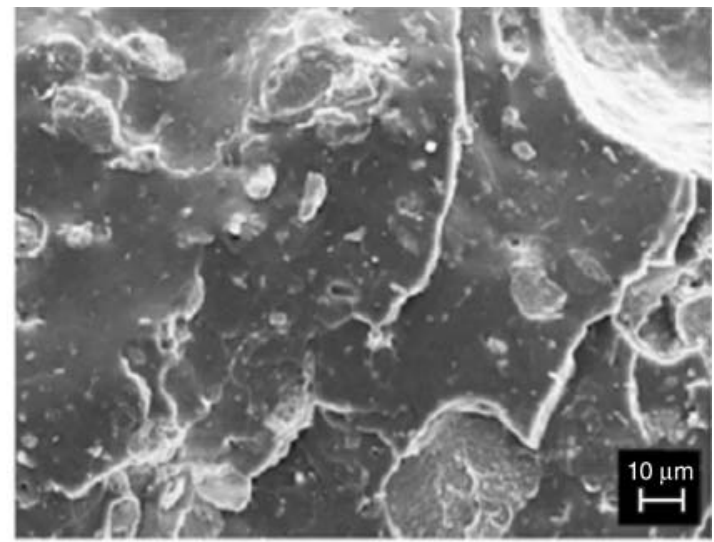

b)

Figure 9. SEM micrographs of the tensile fractured surfaces of a) PTFE ${ }^{0 \mathrm{kGy}}-\mathrm{EPDM}$ and b) PTFE $500 \mathrm{kGy}-\mathrm{EPDM}^{\mathrm{b}}$ blends

nanopowder being inert remained as huge rounded agglomerates even under high shearing. This behavior can also be seen in microdispersion in EPDM matrix. Figures $9 a$ and $9 b$ shows SEM micrographs of the tensile fractured surfaces of PTFE $\mathrm{kGy}_{-}$ EPDM and PTFE500 kGy-EPDM. It is evident that the surface features are apparently distinguishable from each other. The PTFE $500 \mathrm{kGy}$-EPDM vulcanizate surface is smooth, with agglomerates embedded and homogenously dispersed in the EPDM matrix while PTFE 0 kGy-EPDM shows an uneven, inhomogeneous surface with large vacuoles on the fractured surface. This indicates that the PTFE particles are being pulled out of the matrix on application of stress due to the absence of interfacial interaction or coupling with the matrix. It can be observed that the non-modified PTFE particles are bigger in size and tend to form huge irregular agglomerates in the EPDM matrix even under high shearing during blending operation. Non-modified L100X PTFE particles lack both the compatibility and the dispersion efficiency. Figure 10 shows the

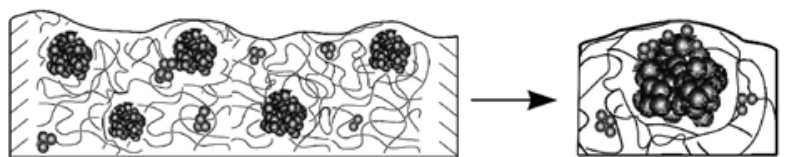

a)

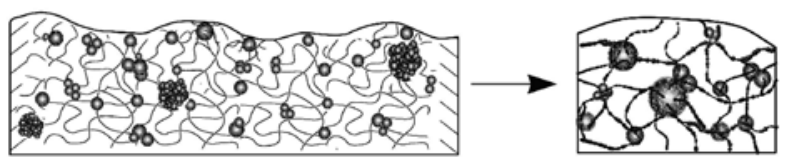

b)

Figure 10. Schematics of the (a) non-modified and (b) modified PTFE nanopowder in EPDM

schematics of the (a) non-modified and (b) modified PTFE nanopowder in EPDM.

\subsection{DSC investigations}

Figure 11 shows the thermal traces of (a) non-modified and $500 \mathrm{kGy}$ irradiated PTFE nanopowder and (b) corresponding blends PTFE ${ }^{0}$ Gy-EPDM and PTFE 500 kGy-EPDM. The crystallization peak of $500 \mathrm{kGy}$ irradiated PTFE nanopowder shifts to a lower temperature of about $303.5^{\circ} \mathrm{C}$. Also, the crys- 


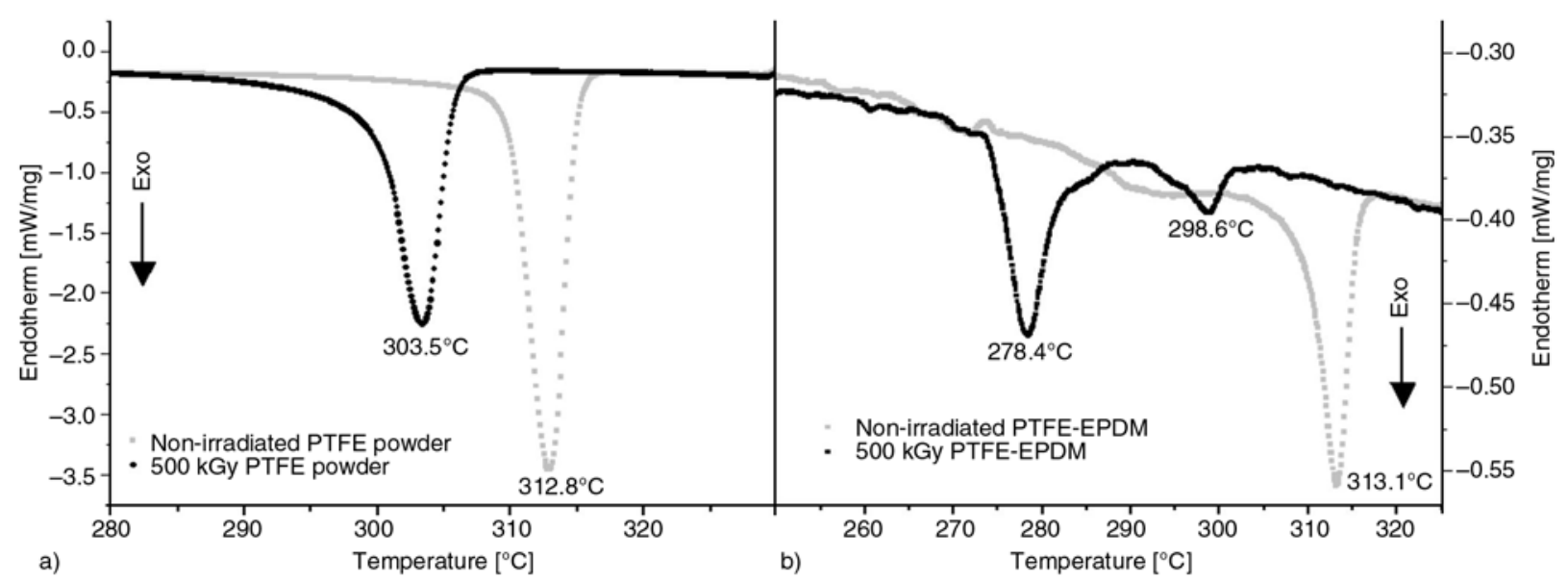

Figure 11. DSC cooling scans of the non-irradiated and $500 \mathrm{kGy}$ irradiated PTFE nanopowder (a), and their corresponding EPDM blends (b)

tallization onset occurred at lower temperature and continued down to approx. $290^{\circ} \mathrm{C}$. These distinct variations in $500 \mathrm{kGy}$ compared to non-modified PTFE nanopowder is due to the electron beam treatment process which caused degradation of 500 kGy PTFE nanopowder. The molecular weight decreases due to chain scission and leads to PTFE macromolecules of different chain lengths. As a result, the crystallization peak occurs at lower temperatures and the crystallization process continues till much lower temperatures in comparison to the non-modified PTFE nanopowder.

In case of blends, PTFE $500 \mathrm{kGy}-\mathrm{EPDM}$ shows two crystallization peaks located at distinct temperatures. The second crystallization step at lower temperature also called fractionated crystallization occurred at $278^{\circ} \mathrm{C}$ along with the bulk crystallization peak at $298^{\circ} \mathrm{C}$ [34-35]. The area of the first bulk crystallization peak is smaller as compared to the area of the second peak. However, the crystallization temperature $\left(298.6^{\circ} \mathrm{C}\right)$ of the first peak is close to $500 \mathrm{kGy}$ irradiated PTFE nanopowder $\left(303.5^{\circ} \mathrm{C}\right)$. The first crystallization peak is attributed to the content of PTFE nanopowder in EPDM having comparatively bigger and incompatible agglomerates. The PTFE agglomerates could be compatibilized only on the surface and the core consists of pure agglomerated PTFE nanopowder. These agglomerates show crystallization temperatures similar to pure PTFE bulk crystallization. However, for PTFE $\mathrm{kGy}^{\mathrm{E}} \mathrm{EPDM}$, no fractionated crystallization except bulk crystallization similar to non-irradiated PTFE powder is observed at $313^{\circ} \mathrm{C}$. This stems from the fact that non-irradiated PTFE nanopowder is difficult to de-agglomerate and disperse homogeneously. The variations in the position of the transition-melting peaks observed in PTFE500 kGy-EPDM is due to the specific chemical compatibility of the electron beam modified PTFE with EPDM. This unique fractionated crystallization behaviour is mainly due to the fine dispersion of $500 \mathrm{kGy}$ irradiated PTFE nanopowder in EPDM. The outstanding dispersion of $500 \mathrm{kGy}$ irradiated PTFE nanopowder is also attributed to its smaller particle size and enhanced compatibility as is evident in Figure 8. PTFE ${ }^{0}$ kGy-EPDM on the other hand has significantly poor dispersion and compatibility with EPDM.

\subsection{Physical properties}

Figures $12 \mathrm{a}$ and $12 \mathrm{~b}$ show tensile strength and elongation at break of PTFE-EPDM blends as a function of absorbed irradiation dose. The horizontal line represents EPDM gum. In case of PTFE $\mathrm{kGy}_{-}$ EPDM, tensile strength and elongation at break are lower than modified PTFE filled EPDM. With increasing absorbed dose, tensile strength and elongation at break of modified PTFE coupled EPDM compounds increase systematically. Tensile strength and elongation at break of EPDM gum and PTFE $^{0 \mathrm{kGy}-E P D M}$ are almost the same because of poor compatibility and dispersion. On the other hand, PTFE500 kGy-EPDM shows the highest tensile strength and elongation at break. Modified PTFE particles having smaller agglomerate sizes and compatible surfaces enhance its degree of dispersion and compatibility. The improvement of physi- 

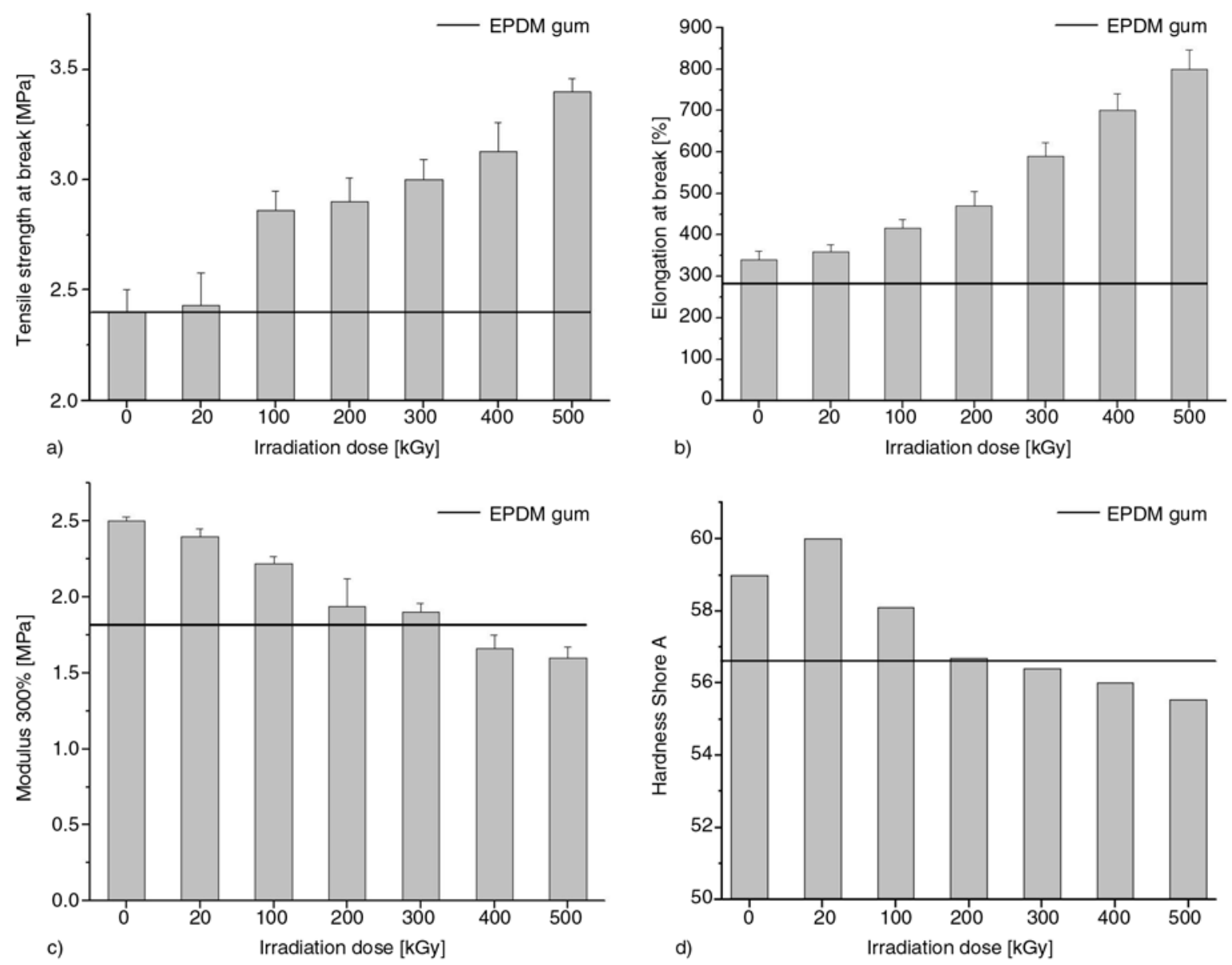

Figure 12. Tensile strength at break (a), elongation at break (b), modulus $300 \%$ (c) and hardness (d) as a function of absorbed dose of PTFE nanopowder in EPDM

cal properties of EPDM filled with electron treated PTFE is essentially due to the synergistic effect of their homogeneous dispersion and desirable compatibility. Figure $12 \mathrm{c}$ displays the stress at $300 \%$ elongation (so-called modulus 300\%, M300) as a function of absorbed dose. The M300 decreases for modified PTFE filled EPDM with increasing irradiation dose. PTFE ${ }^{0}$ kGy-EPDM shows the highest M300. However, the corresponding values of PTFE $^{400} \mathrm{kGy}_{\text {-EPDM }}$ and PTFE $500 \mathrm{kGy}$-EPDM are lower even than EPDM gum. Figure 12d shows the corresponding Shore A hardness values of PTFEEPDM blends. The effect of absorbed dose of PTFE nanopowder on vulcanizate hardness can be seen in their decreasing values of hardness. EPDM filled with PTFE having absorbed irradiation doses higher than $20 \mathrm{kGy}$ results in decreasing hardness values of PTFE-EPDM blends. PTFE 20 kGy-EPDM has the highest hardness while PTFE500 kGy-EPDM showed the lowest. It is interesting to note that hardness of the blends above PTFE 200 kGy-EPDM is even lower than that of EPDM gum. Non-modified PTFE nanopowder as shown in Figure 8 and 9 are huge uncovered agglomerates dispersed as solid rigid bodies in a matrix. Being incompatible they are not covered by EPDM molecules and hence tend to segregate in EPDM matrix. The presence of these huge inert bodies provides strength and hardness to the host matrix.

\subsection{Reaction mechanism}

The lack of reinforcement or compatibility of PTFE with other polymers is due to its inherent inert molecular structure. However, surface modification by high-energy electrons provides compatibility between PTFE and an unsaturated rubber matrix by a radical coupling reaction. The radicals of the irradiated PTFE react with olefinic unsaturated groups of EPDM as shown in Figure 13. Since several EPDM molecules are coupled to the surface of PTFE particles, these inter-chain bonds between 


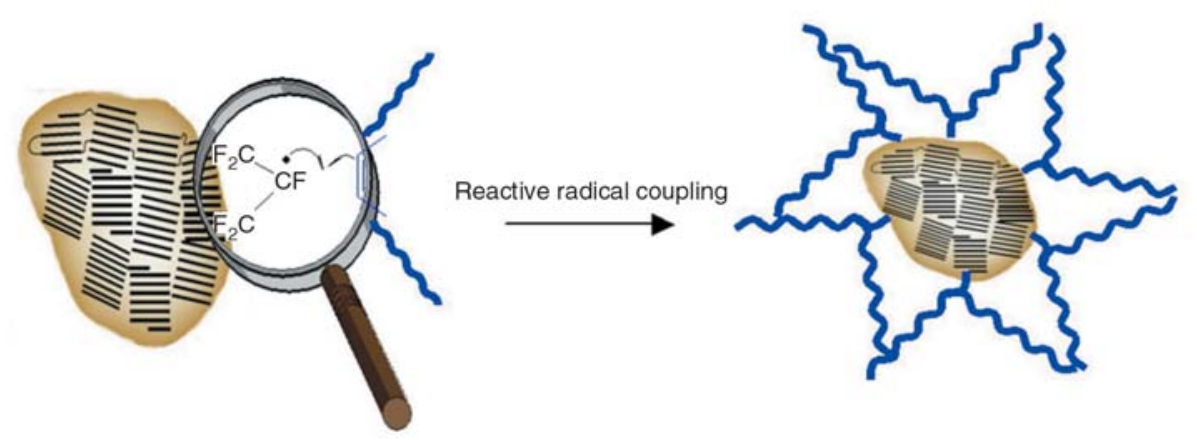

Figure 13. Radical coupling mechanism of modified PTFE radicals and the unsaturated diene EPDM

PTFE and EPDM provide compatibility by strong intermolecular network formation, the result of which is obvious in the improved physical properties of modified PTFE-EPDM blends.

\section{Conclusions}

We have described a method to develop PTFE coupled EPDM compounds with desired physical properties by simple, easy and effective controlledmodification of PTFE nanopowder. The existence of compatibility between modified PTFE nanopowder and EPDM was revealed by TEM, DSC and SEM. The resultant modified PTFE-EPDM blends demonstrate exceptionally enhanced physical properties by enwrapping of modified PTFE nanopowder by EPDM. Water contact angles indicate that the wettability of the modified PTFE nanopowder was increased by functional groups compared with non-modified PTFE nanopowder. The synergistic effect of enhanced compatibility by chemical coupling and micro-dispersion of PTFE agglomerates results in a significant improvement of physical properties of PTFE coupled EPDM compounds. In conclusion, PTFE coupled EPDM compounds prepared by the described approach offer the potential use of PTFE nanopowder in wide range of polymers for special purpose applications. Accordingly, they are promising in various fields.

\section{Acknowledgements}

We thank Solvay Solexis S.p.A. (Italy) for the free of charge supply of the special L100X PTFE nanopowder grade and U. Gohs for assisting in carrying out electron beam irradiation of PTFE nanopowder.

\section{References}

[1] Gangal S. V.: Tetrafluoroethylene polymers. in 'Encyclopedia of polymer science and engineering' (eds.: Mark. H. F., Bikales N. M., Overberger C. G., Menges G.) Wiley, New York, Vol. 16, 577-600 (1989).

[2] Drobny J. G.: Fluoropolymers in automotive applications. Polymers for Advanced Technologies, 18, 117 121 (2007).

[3] Morgan R. A., Stewart C. W., Thomas E. W., Stahl W. M.: Reinforcement with fluoroplastic additives. Rubber World, 204, 25-28 (1991).

[4] Crandell W. H.: Evaluation of silicon rubber modified with teflon. Rubber World, 236-240 (1955).

[5] Kaufman M. H., Gonzales J.: Reinforcement of fluoroelastomers with halopolymers. Rubber Chemistry and Technology, 41, 527-532 (1968).

[6] Akinay E., Tinçer T.: Radiation grafting of vinyl monomers onto poly(tetrafluoroethylene) powder produced by $\gamma$ irradiation and properties of grafted poly(tetrafluoroethylene) filled low density polyethylene. Journal of Applied Polymer Science, 79, 816-826 (2001).

[7] Ji L. Y., Kang E. T., Neoh K. G., Tan K. L.: Oxidative graft polymerization of aniline on PTFE films modified by surface hydroxylation and silanization. Langmuir, 18, 9035-9040 (2002).

[8] Yu W. H., Kang E. T., Neoh K. G.: Controlled grafting of comb copolymer brushes on poly(tetrafluoroethylene) films by surface-initiated living radical polymerizations. Langmuir, 21, 450-456 (2005).

[9] Zhang M. C., Kang E. T., Neoh K. G., Tan K. L.: Consecutive graft copolymerization of glycidyl methacrylate and aniline on poly(tetrafluoroethylene) films. Langmuir, 16, 9666-9672 (2000).

[10] Kouichi K., Sato H., Katsuyama H..: Thiopyrylium compounds and photoconductive compositions containing said compounds. US patent 4469864, USA (1984).

[11] Feiring A. E., Imbalzano J. F., Kerbow D. L.: Developments in commercial fluoroplastics. Trends in Polymer Science, 2, 26-31 (1994). 
[12] Hillmyer M. A., Lodge T. P.: Synthesis and self assembly of fluorinated block-copolymers. Journal of Polymer Science, Part A: Polymer Chemistry, 40, 1-8 (2002).

[13] Lunkwitz K., Lappan U., Lehmann D.: Modification of fluoropolymers by means of electron beam irradiation. Radiation Physics and Chemistry, 57, 373-376 (2000).

[14] Lappan U., Lunkwitz K.: Radiation induced functionalization of fluoropolymers. Zeitschrift für Physikalisch Chemie, 191, 209-218 (1995).

[15] Lappan U., Geißler U., Lunkwitz K.: Electron beam irradiation of polytetrafluoroethylene in vacuum at elevated temperature: An infrared spectroscopy study. Journal of Applied Polymer Science, 74, 1571-1576 (1999).

[16] Lunkwitz K., Brink H-J., Handte D., Ferse A.: The radiation degradation of polytetrafluoroethylene resulting in low-molecular and functionalized perfluorinated compounds. Radiation Physics and Chemistry, 33, 523-532 (1988).

[17] Jun T., Quinji X.: Surface modification of PTFE by ${ }^{60} \mathrm{co} \gamma$-ray irradiation. Journal of Applied Polymer Science, 69, 435-441 (1998).

[18] Dorschner H., Lappan U., Lunkwitz K.: Electron beam facility in polymer research: radiation induced functionalization of polytetrafluoroethylene. Nuclear Instruments and Methods In Physics Research, Section B, 139, 495-501 (1998).

[19] Cheng S., Kerluke D. R.: Radiation processing for modification of polymers. in 'Annual Technical Conference of the Society of Plastic Engineering (ANTEC) IBA, Advanced Materials Division, 7695 Formula Place. San Diego, USA' (2003).

[20] Jun T., Qunji X.: Surface modification of PTFE by ${ }^{6} 0$ co $\gamma$-ray irradiation. Journal of Applied Polymer Science, 69, 435-441 (1998).

[21] Lehmann D., Hupfer B., Lappan U., Pompe G., Häußler L., Jehnichen D., Janke A., Geißler U., Reinhardt R., Lunkwitz K., Franke R., Kunze K.: New PTFE-polyamide compounds. Designed Monomers and Polymers, 5, 317-324 (2002).

[22] Lehmann D., Hupfer B., Lappan U., Geißler U., Reinhardt R., Lunkwitz K.: Neue PolytetrafluoroethylenPolyamid Compounds. Materialwissenschaft und Werkstofftechnik, 31, 666-668 (2000).

[23] Franke R., Lehmann D., Kunze K.: Tribological behaviour of new chemically bonded PTFE polyamide compounds. Wear, 262, 242-252 (2007).
[24] Klüpfel B., Lehmann D., Heinrich G., Linhart C., Haberstroh E., Kunze K., Hufenbach W., Dallner C., Künkel R., Ehrenstein G. W.: Kopplung von PTFE und Kautschuk- Eine neue elastomere Werkstoffklasse. Kautschuk Gummi Kunststoffe, 58, 226-229 (2005).

[25] Haberstroh E., Linhart C., Epping K., Schmitz T.: Verbesserte tribologische Eigenschaften von Elastomeren durch PTFE Pulver. Kautschuk Gummi Kunststoffe, 59, 447-453 (2006).

[26] Lee B-L., Patel R., Cox M., Andries J. C.: Polyvinyl chloride or polyolefin melt processable compositions containing polytetrafluoroethylene micropowder. US patent 6977280, USA (2005).

[27] Lahijani J.: Melt-fabricable polytetrafluoroethylene. US patent 6265492, USA (2003).

[28] Khan M. S., Lehmann D., Heinrich G.: Properties of the EPDM with modified PTFE nanopowder. Kautschuk Gummi Kunststoffe, 60, 226-234 (2007).

[29] Khan M. S., Lehmann D., Heinrich G., Franke R.: Physical and tribological properties of the modified PTFE nanopowder filled EPDM. Wear, in press (2008).

[30] Khan M. S., Franke R., Lehmann D., Heinrich G.: Friction and wear behaviour of PTFE nanopowderEPDM compounds. Wear, in press (2008).

[31] Golden J. H.: The degradation of polytetrafluoroethylene by ionizing radiation. Journal of Polymer Science, 45, 534-536 (1960).

[32] Hagiwara M., Tagawa T., Amemiya H., Araki K., Shinohara J., Kagiya T.: Mechanism of thermal decomposition of peroxide radicals formed in polytetrafluoroethylene by $\gamma$-ray irradiation. Journal of Polymer Science, Polymer Chemistry, 14, 2167-2172 (1976).

[33] Fisher W. K., Corelli J. C.: Effect of ionizing radiation on the chemical composition, crystalline content and structure, and flow properties of polytetrafluoroethylene. Journal of Polymer Science, Polymer Chemistry, 19, 2465-2493 (1981).

[34] Häussler L., Pompe G., Lehmann D., Lappan U.: Fractionated crystallization in blends of functionalized poly(tetrafluoroethylene) and polyamide. in 'International Symposium on Reactive Polymers in Inhomogeneous Systems, in Melts and at Interfaces, Dresden, Germany' vol 164, 411-419 (2001).

[35] Pompe G., Häussler L., Pötschke P., Voigt D., Janke A., Geißler U., Hupfer B., Reinhardt G., Lehmann D.: Reactive polytetrafluoroethylene/polyamide compunds. I. Characterization of the compound morphology with respect to the functionality of the polytetrafluoroethylene component by microscopic and differential scanning calorimetry studies. Journal of Applied Polymer Science, 98, 1308-1316 (2005). 